\title{
Sagittal Parameters of Spine and Pelvis in Young Adults Using the EOS Imaging System: Prospective Study of 92 Asymptomatic Subjects
}

\author{
Youn Moo Heo ${ }^{1,2}$, Tae Kyun Kim ${ }^{1,2}$, Min Gu Jang ${ }^{1,2}$, Jae Kyu Choi ${ }^{1,2}$ \\ ${ }^{1}$ Department of Orthopaedic Surgery, Konyang University College of Medicine, Daejeon, Korea \\ ${ }^{2}$ Konyang University Myunggok Research Institute for Medical Scienece, Konyang University College of Medicine, Daejeon, Korea
}

\begin{abstract}
Study Design: This study adopted a prospective study design to evaluate the sagittal parameters of the spine and pelvis in young adults using the EOS imaging system.

Purpose: This study was designed to analyze spinopelvic sagittal alignment measurement values obtained using the EOS imaging system in asymptomatic young adults.

Overview of Literature: Sagittal alignment of the spine and pelvis is important in diagnosing and treating spinal diseases. We usually take sagittal images using whole-spine standing lateral radiography. Recently, the EOS imaging system, which uses a low-dose radiation in a weight-bearing state, was developed. So, we studied the sagittal parameters of the spine and pelvis in young adults by using the EOS imaging system.

Methods: We recruited young adults aged 20-30 years and explained the EOS imaging system. They voluntarily participated in the study. We took full-body standing orthogonal anteroposterior and lateral images using the EOS imaging system (EOS imaging, Paris, France). Then, we measured the pelvic incidence (PI), sacral slope (SS), pelvic tilt (PT), sagittal vertical axis (SVA), T1/T12 kyphosis, and L1/S1 lordosis. We analyzed each parameter using Student $t$-test, paired $t$-test, and Pearson's correlation coefficient.

Results: Ninety-two patients were enrolled in the study. The average PI and SS were $47.18^{\circ}$ and $36.03^{\circ}$, respectively. Moreover, PT and SVA were $11.17^{\circ}$ and $-10.15 \mathrm{~mm}$, respectively. T1/T12 kyphosis was $37.37^{\circ}$, while L1/S1 lordosis was $46.64^{\circ}$. All parameters were enough for normal distribution. Pearson correlation coefficient analysis showed a meaningful correlation between $\mathrm{Pl}$ and SS and $\mathrm{Pl}$ and $\mathrm{PT}(R>0.6, p<0.05)$.

Conclusions: Measuring spinal and pelvic sagittal values is important. Sagittal parameters could help decide how to operate patients with spinal diseases. We attempted to obtain sagittal values using the EOS imaging system. These parameters could help preoperatively estimate the lumbar lordosis restoration and could also be used as guidelines for spinopelvic sagittal balance.
\end{abstract}

Keywords: Spine; Pelvis; Whole body imaging; Postural balance

\section{Introduction}

Determining the average spinopelvic sagittal alignment value according to age is important in judging abnormalities of the spinal sagittal curvature. Many studies have reported the importance of spinopelvic sagittal alignment

Received Apr 6, 2021; Revised Oct 3, 2021; Accepted Oct 5, 2021

Corresponding author: Tae Kyun Kim

Department of Orthopaedic Surgery, Konyang University College of Medicine, 158 Gwanjeodong-ro, Seo-gu, Daejeon 35365, Korea

Tel: +82-42-600-9120, Fax: +82-42-545-2373, E-mail: ktk1113@kyuh.ac.kr 
[1]. Banno et al. [2] have reported that knowledge of agerelated normal spinal parameters is essential for understanding adult spinal deformities. Moreover, Gutman et al. [3] have reported that the global spinal value plays an important role in surgical planning and in attempting to minimize the incidence of complications, such as adjacent segment disease, sagittal imbalance, and implant failure. Shimokawa et al. [4] have also reported on the relationship between sagittal parament and quality of life.

So far, spinopelvic sagittal alignment has been evaluated using standing lateral radiography, which is a simple, inexpensive, and easy method. However, each image must be taken separately to measure the spinopelvic alignment and combined with other images. This process can cause distortion of the radiography images, which increases the risk of size measurement error of structures [5].

According to a study, the average radiation dose was 0.68 mrad for EOS-Fast, $0.73 \mathrm{mrad}$ for computed tomography (CT) scanogram, and $29.01 \mathrm{mrad}$ for conventional radiography [6]. Moreover, the EOS test had a lower radiation dose than CT or conventional radiography. In another study, EOS photography had the advantage of having a lower irradiation volume by at least 3-9 times for each body part than conventional radiography [7]. Many studies on the measurement of spinopelvic sagittal alignment using whole-spine standing lateral radiography have been conducted [8-10]. However, we found only few studies that measured spinopelvic sagittal alignment using the EOS imaging system. Thus, we examined spinopelvic sagittal alignment in asymptomatic young adults using the EOS imaging system and determined the differences in the measurement values among the imaging modalities.

\section{Materials and Methods}

This prospective study was approved by the Institutional Review Board of Konyang University Hospital (IRB no., 2017-02-007-009).

\section{Subjects}

We visited each department in Konyang University in November 2016. We explained the research topic and EOS imaging system to the students and persuaded them to participate in the study. All students provided their consent and voluntarily participated in this study. The conditions applied were as follows.
The inclusion criteria were as follows [1]: absence of spinal disease or deformity [2]; no history of hip, pelvic, or lower limb disorders [3]; and no history of spinal, pelvic, or lower limb surgeries. Students with a history of low back pain for a minimum of 3 consecutive months were excluded from the study. Moreover, we obtained information regarding age, sex, height, and weight.

The subjects were instructed to stand comfortably on both feet, with the knees extended and fingertips covering both eyes during the examination using the EOS imaging system (Fig. 1). While filming EOS, we decided on the posture as above, considering the posture in which the subjects could be comfortable while the vertebral body is not obscured $[11,12]$.

\section{EOS system}

The EOS system shown in Fig. 2 is a new slot-scanning radiological device that allows the acquisition of two radiographic images simultaneously. It is composed of two

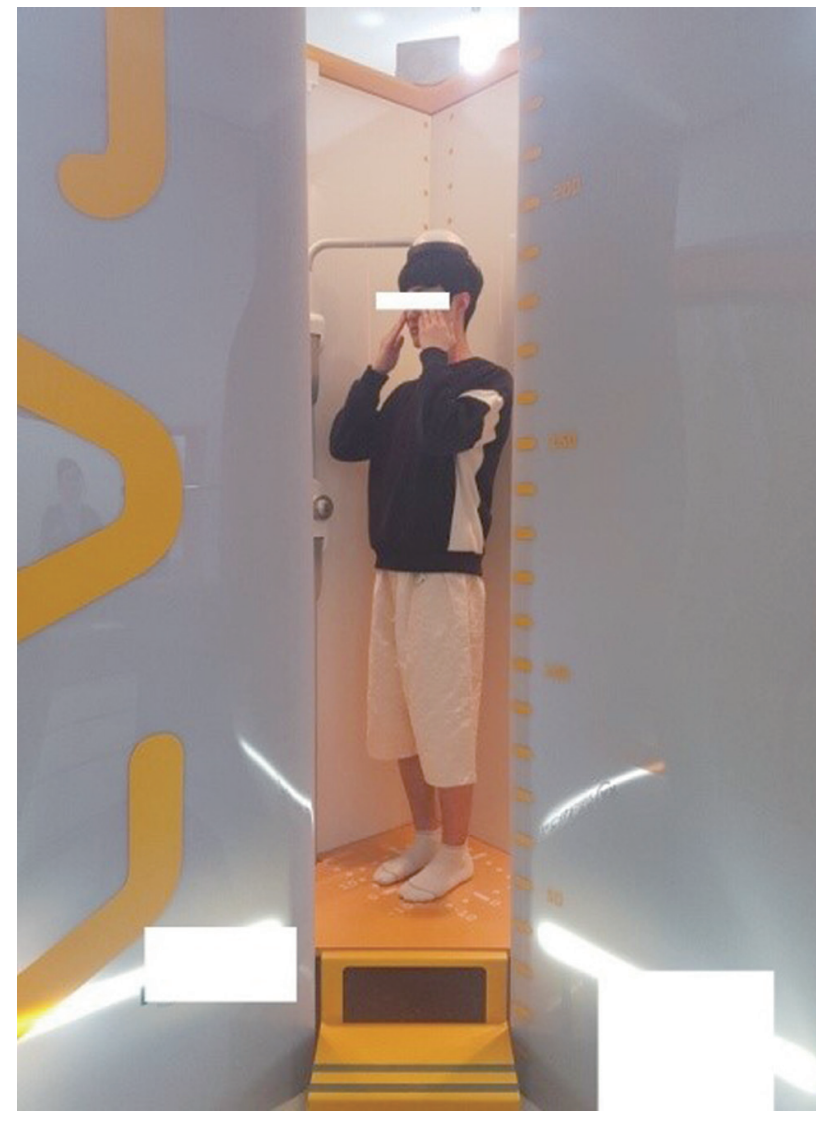

Fig. 1. During the examination, the subjects are asked to stand comfortably with both feet side by side, knees flat, and fingertips covered both eyes. 


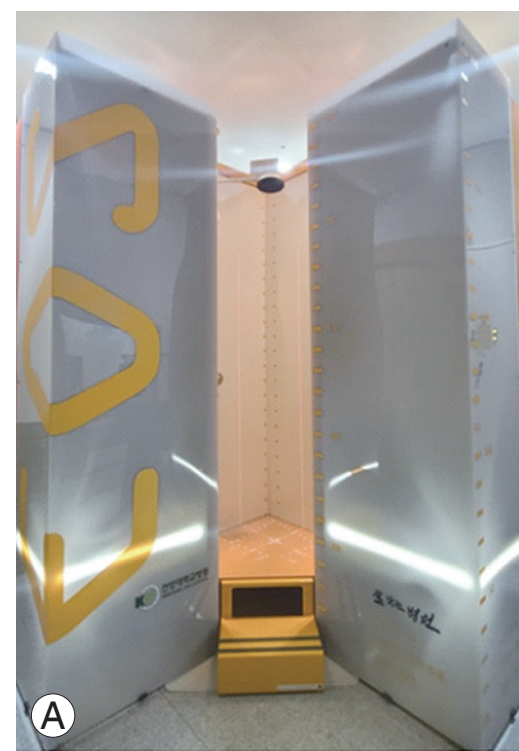

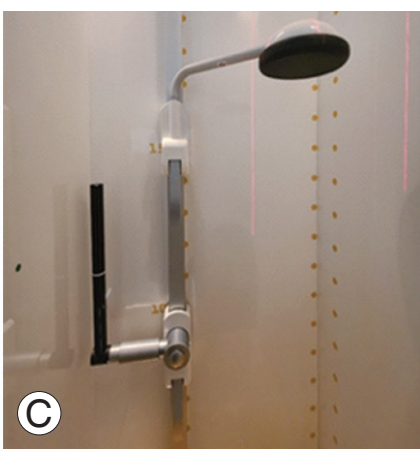

Fig. 2. (A) An EOS system cabin (EOS imaging, Paris, France), an open rectangular cage that is $2 \mathrm{~m}$ wide and $2.7 \mathrm{~m}$ tall. (B) An EOS system cabin that scans the patient in the standing position in two orthogonal planes. (C) An X-ray tube and a sensor installed at a $90^{\circ}$ angle, taking images from all sides at the same time, and a safety bar and device fixing the patient's head in place while the image is obtained.
$\mathrm{X}$-ray resources, shaped as fan beams through collimation slits. The sources are coupled with linear detectors built using the micromesh gaseous structure technology [13].

The distance between the sources and detectors is 1.3 $\mathrm{m}$, with the patient standing at approximately $1 \mathrm{~m}$ of both sources. The two source-detector pairs are positioned orthogonally, so the patient's face and profile images are generated line-by-line while the entire system is vertically translated. Moreover, the system could activate only one source for single-view image acquisition. The user determines the starting and final heights of the vertical scan. This way, irradiation to body parts outside the region of interest is minimized. For spinal examination, the scan time lasts approximately 8-15 seconds, depending on the patient's height. Patients are instructed to hold their breath while touching both fingers on the cheek during the scan. As images are taken simultaneously, no patient movement is recorded between each radiograph. This characteristic benefits techniques, such as the three-dimensional reconstruction of bony structures from two radiographic views, because their accuracy depends strongly on the spatial correspondence of the structures from one view to the other (Fig. 3) [14,15].

\section{Measurement parameters}

We took standing anteroposterior (AP) and lateral (LAT) images, including the cervical, thoracic, lumbar, and hip joints, and created images using the EOS imaging system
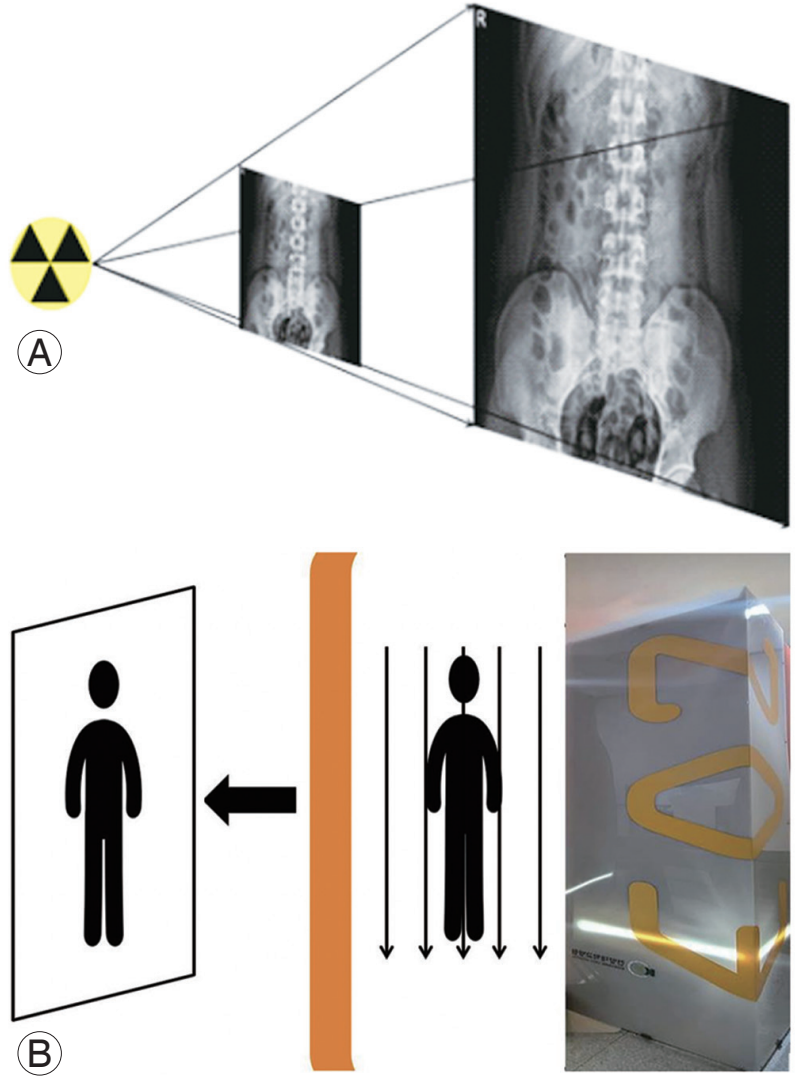

Fig. 3. (A) A radiograph that was enlarged when compared with the original projection owing to the distortion created by the conical projection from the center to the edges of the radiograph. The farther the structure is from the central region, the greater the scale of error. (B) In the EOS imaging system (EOS imaging, Paris, France), the radiograph is at the same scale as the original projection owing to the low dose of $X$-ray beam that passes through the subject and Charpak's chamber. The low dose of $\mathrm{X}$-rays gets amplified by increased flow of photons inside the chamber. 
(EOS imaging, Paris, France). Digital images were stored in the institutional Picture Archiving and Communication System (PACS) network (Marosis v5.4.10.68; INFINITT Healthcare Co. Ltd., Seoul, Korea). Conventional curve measurements were manually performed on digital anteroposterior and lateral EOS two-dimensional images, using standard PACS workstation software tools (sterEOS; Biospace Med, Paris, France).

Pelvic parameters were measured using the pelvic incidence (PI), sacral slope (SS), and pelvic tilt (PT). Sagittal balance was measured using the sagittal vertical axis (SVA), T1/T12 kyphosis, and L1/L5 lordosis. PI was defined as the angle between a line drawn from the center of the hip axis to the center of the superior endplate of S1 and perpendicular to the endplate [16]. SS was defined as the angle formed between the superior endplate of S1 and horizontal plane from the ground. PT was defined as the angle between the vertical plane from the ground and a straight line connecting the center of the superior endplate of S1 to the centers of the femoral heads.

SVA was defined as the distance between the vertical axis passing through the center of $\mathrm{C} 7$ vertebral body and posterior edge of the sacral plate. SVA is positive when the vertical axis passing through $\mathrm{C} 7$ is anterior to the posterior edge of the sacral plate. T1/T12 kyphosis and L1/L5
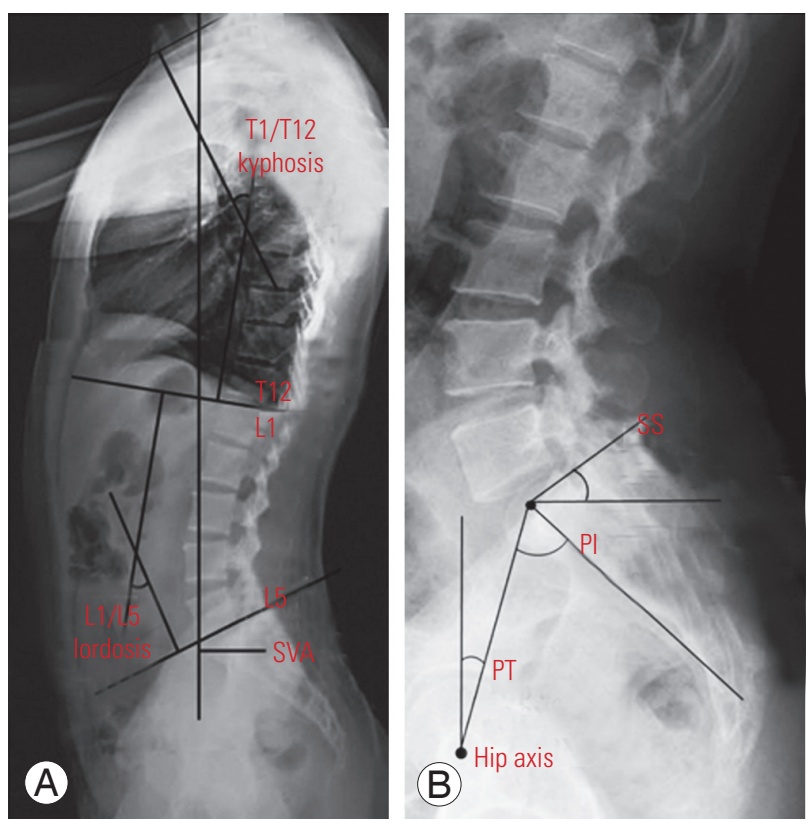

Fig. 4. (A, B) The following six items were measured with the EOS imaging system (EOS imaging, Paris, France): pelvic incidence (PI), sacral slope (SS), sagittal pelvic tilt (PT), sagittal vertical axis (SVA), T1/T12 kyphosis, and L1/L5 lordosis. lordosis were defined as the angles between the superior endplate of the upper vertebral body and the lower endplate of the lower vertebral body (Fig. 4).

\section{Statistical analysis}

We analyzed the mean value and standard deviation of the parameters of males and females separately using Student $t$-test (i.e., PI, SS, PT, SVA, T1/T12 kyphosis, and L1/L5 lordosis). Moreover, we analyzed the correlations of the radiological parameters, sex, and body mass index (BMI) using Pearson's correlation coefficient as follows: 0.00-0.20, poor; $0.21-0.40$, fair; $0.41-0.60$, moderate; $0.61-0.80$, good; and 0.81-1.00, excellent. All $p$-values of less than 0.05 were used to denote statistical significance. All statistical analyses were performed using IBM SPSS ver. 20.0 (IBM Corp., Armonk, NY, USA).

\section{Results}

Ninety-two participants were enrolled in this study, including 65 women and 27 men, all of whom were Korean. The mean age of the subjects was 21.5 years. The mean BMI was $21.5 \pm 2.83 \mathrm{~kg} / \mathrm{m}^{2}$ (range, $16-32 \mathrm{~kg} / \mathrm{m}^{2}$ ). The mean spinopelvic parameter values of the cohort were $47.18^{\circ} \pm 9.15^{\circ}$ for PI, $11.17^{\circ} \pm 6.22^{\circ}$ for PT, $36.03^{\circ} \pm 6.91^{\circ}$ for SS, $-10.15 \pm 20.98 \mathrm{~mm}$ for SVA, $46.64^{\circ} \pm 10.52^{\circ}$ for L1/S1 lordosis, and $37.37^{\circ} \pm 8.54^{\circ}$ for $\mathrm{T} 1 / \mathrm{T} 12$ kyphosis (Table 1 ).

The mean spinopelvic parameter values in males were $48.22^{\circ} \pm 9.20^{\circ}$ for PI, $8.74^{\circ} \pm 5.50^{\circ}$ for PT, $39.44^{\circ} \pm 8.13^{\circ}$ for SS, $-5.59 \pm 20.32 \mathrm{~mm}$ for SVA, $49.63^{\circ} \pm 9.43^{\circ}$ for L1/S1 lordosis, and $36.11^{\circ} \pm 6.69^{\circ}$ for T1/T12 kyphosis. Meanwhile, those in females were $46.75^{\circ} \pm 9.17^{\circ}$ for PI, $12.18^{\circ} \pm 6.27^{\circ}$ for PT, and $34.62^{\circ} \pm 5.84^{\circ}$ for SS, $-12.05 \pm 21.11 \mathrm{~mm}$ for SVA, $45.40^{\circ} \pm 10.76^{\circ}$ for $\mathrm{L} 1 / \mathrm{S} 1$ lordosis, and $37.89^{\circ} \pm 9.20^{\circ}$ for $\mathrm{T} 1 /$ T12 kyphosis (Table 2).

All parameters measured were enough to attain a normal distribution. The parameters in males showed a normal distribution in the Kolmogorov-Smirnov test ( $p>0.05)$. In Student $t$-test, SS $(R=0.002, p<0.05)$, SPT $(R=0.015, p<0.05)$, and BMI $(R=0.047, p<0.05)$ were significantly different between the sexes.

Pearson's correlation coefficients between L1/S1 lordosis and SS $(R=0.616, p<0.001)$, PI and SS $(R=0.737, p<0.001)$, and PI and SPT $(R=0.659, p<0.001)$ were all significant (Table 3). Sex had no significant correlation with other variables (Table 4). The correlation between BMI and SVA 
Table 1. Mean, minimum, maximum, and standard deviation of the parameters

\begin{tabular}{lccc} 
Variable & Mean \pm SD & Minimum & Maximum \\
\hline Pelvic incidence $\left({ }^{\circ}\right)$ & $47.18 \pm 9.15$ & 27.00 & 70.00 \\
Sacral slope $\left({ }^{\circ}\right)$ & $36.03 \pm 6.91$ & 20.00 & 65.00 \\
Sagittal vertical axis $(\mathrm{mm})$ & $-10.15 \pm 20.98$ & -77.00 & 3.60 \\
L1/L5 lordosis $\left(^{\circ}\right)$ & $46.64 \pm 10.52$ & 22.00 & 70.00 \\
\hline T1/T12 kyphosis $\left({ }^{\circ}\right)$ & $37.37 \pm 8.54$ & 11.00 & 60.00 \\
\hline
\end{tabular}

SD, standard deviation.

Table 2. Values of the spinopelvic parameters

\begin{tabular}{lccc} 
Variable & Male & Female & $p$-value \\
\hline Pelvic incidence $\left(^{\circ}\right)$ & $48.22 \pm 9.20$ & $46.75 \pm 9.17$ & 0.49 \\
\hline Pelvic tilt $\left(^{\circ}\right)$ & $8.74 \pm 5.50$ & $12.18 \pm 6.27$ & 0.02 \\
\hline Sacral slope $\left(^{\circ}\right)$ & $39.44 \pm 8.13$ & $34.62 \pm 5.84$ & 0.002 \\
\hline Sagittal vertical axis $(\mathrm{mm})$ & $-5.59 \pm 20.32$ & $-12.05 \pm 21.11$ & 0.18 \\
\hline L1/L5 lordosis $\left(^{\circ}\right)$ & $49.63 \pm 9.43$ & $45.40 \pm 10.76$ & 0.08 \\
\hline T1/T12 kyphosis $\left(^{\circ}\right)$ & $36.11 \pm 6.69$ & $37.89 \pm 9.20$ & 0.37 \\
\hline
\end{tabular}

Values are presented as mean \pm standard deviation, unless otherwise stated.

Table 3. Pearson correlation coefficient of PI with other variables

\begin{tabular}{lcc} 
& \multicolumn{2}{c}{ Pearson correlation coefficient } \\
\cline { 2 - 3 } Correlation between PI and & $R$ & $p$-value \\
Sagittal vertical axis & 0.039 & 0.718 \\
Sacral slope & 0.737 & 0.000 \\
Spinopelvic tilt & 0.659 & 0.000 \\
T1/T12 kyphosis & 0.074 & 0.489 \\
\hline L1/S1 lordosis & 0.091 & 0.490 \\
\hline
\end{tabular}

$\mathrm{Pl}$, pelvic incidence.

Table 4. Pearson correlation coefficient of sex with other variables

\begin{tabular}{lcc} 
& \multicolumn{2}{c}{ Pearson correlation coefficient } \\
\cline { 2 - 3 } Correlation between sex and & $R$ & $p$-value \\
\cline { 2 - 3 } Sagittal vertical axis & -0.030 & 0.807 \\
Sacral slope & -0.090 & 0.403 \\
\hline Spinopelvic tilt & -0.014 & 0.897 \\
\hline T1/T12 kyphosis & 0.087 & 0.419 \\
\hline L1/S1 lordosis & 0.046 & 0.670 \\
\hline
\end{tabular}

( $R=0.214, R=0.04 ; p<0.05)$ was significant in the Pearson correlation analysis (Tables 5,6$)$.
Table 5. Results of the Pearson correlation coefficient

\begin{tabular}{|c|c|c|}
\hline \multirow{2}{*}{ Variable } & \multicolumn{2}{|c|}{ Pearson correlation coefficient } \\
\hline & $R$ & $p$-value \\
\hline \multicolumn{3}{|c|}{ Correlation between sacral slope and } \\
\hline L1/S1 lordosis & 0.616 & $<0.001$ \\
\hline $\mathrm{PI}$ & 0.737 & $<0.001$ \\
\hline \multicolumn{3}{|c|}{ Correlation between spinopelvic tilt and } \\
\hline $\mathrm{PI}$ & 0.659 & $<0.001$ \\
\hline \multicolumn{3}{|c|}{ Correlation between body mass index and } \\
\hline Sagittal vertical axis & 0.214 & 0.004 \\
\hline
\end{tabular}

Table 6. Results of the Pearson correlation coefficient between BMI and other parameters

\begin{tabular}{lcc} 
& \multicolumn{2}{c}{ Pearson correlation coefficient } \\
\cline { 2 - 3 } Correlation between BMI and & $R$ & $p$-value \\
\hline Pelvic incidence & 0.058 & 0.588 \\
\hline Sacral slope & 0.045 & 0.674 \\
Spinopelvic tilt & 0.006 & 0.959 \\
\hline T1/T12 kyphosis & -0.084 & 0.436 \\
\hline L1/S1 lordosis & 0.026 & 0.812 \\
\hline
\end{tabular}

BMI, body mass index.

\section{Discussion}

Many researchers have evaluated spinopelvic sagittal alignment owing to its importance in treating spinal diseases and the overall spinal health. Zhu et al. [17] have examined sagittal alignment in Chinese populations, and Sangondimath et al. [18] have examined spinal and sagittal alignment of the pelvis in asymptomatic Indian individuals. The normal values of the sagittal parameters in Chinese populations could be significantly influenced by age, weight, and sex. Chinese populations showed sig- 
Table 7. Comparison of the studies of pelvic parameters

\begin{tabular}{|c|c|c|c|c|c|c|}
\hline \multirow{3}{*}{ Variable } & \multicolumn{3}{|c|}{ EOS } & \multicolumn{3}{|c|}{ Radiography } \\
\hline & \multicolumn{3}{|c|}{ Present study } & \multirow{2}{*}{$\frac{\text { Lee et al. [1] }}{\text { Whole group }}$} & \multirow{2}{*}{$\frac{\text { Zhu et al. [17] }}{\text { Whole group }}$} & \multirow{2}{*}{$\frac{\text { Le Huec and Hasegawa [19 }}{\text { Whole group }}$} \\
\hline & Male & Female & Whole group & & & \\
\hline Pelvic incidence $\left({ }^{\circ}\right)$ & $48.22 \pm 9.20$ & $46.75 \pm 9.17$ & $47.18 \pm 9.15$ & $47.8 \pm 9.3$ & $44.6 \pm 11.2$ & $52.0 \pm 10.5$ \\
\hline Pelvic tilt $\left({ }^{\circ}\right)$ & $8.74 \pm 5.50$ & $12.18 \pm 6.27$ & $11.17 \pm 6.22$ & $11.5 \pm 5.3$ & $11.2 \pm 7.8$ & $11.6 \pm 7.0$ \\
\hline Sacral slope $\left(^{\circ}\right)$ & $39.44 \pm 8.13$ & $34.62 \pm 5.84$ & $36.03 \pm 6.91$ & $36.3 \pm 7.8$ & $32.5 \pm 6.5$ & $40.2 \pm 7.7$ \\
\hline Kyphosis ( $\left(^{\circ}\right)$ & $36.11 \pm 6.69$ & $37.89 \pm 9.20$ & $37.37 \pm 8.54$ & - & - & $41.4 \pm 9.8$ \\
\hline Lordosis $\left({ }^{\circ}\right)$ & $49.63 \pm 9.43$ & $45.40 \pm 10.76$ & $46.64 \pm 10.52$ & - & - & $55.8 \pm 10.2$ \\
\hline
\end{tabular}

Values are presented as mean \pm standard deviation.

nificantly smaller PI and SS than Caucasian populations. Lee et al. [1] have evaluated sagittal alignment in a Korean young adult population. The patterns of sagittal alignment showed individual differences and can be classified into three types with significantly different sagittal parameters. Le Huec and Hasegawa [19] have concluded that spinopelvic parameters were comparable between Japanese and Caucasian subjects. The differences in some parameters (i.e., L5-S1 lumbar lordosis, L1-L5 lumbar lordosis, and T4-T12 kyphosis), such as PI, PT, and SS, could be explained by the different habits (e.g., squatting) between Caucasian and Japanese individuals. Unlike other studies, we measured the spinopelvic sagittal values using the EOS imaging system. The EOS shooting method is different from that of ordinary radiography. Thus, we thought that the data obtained would be different from those reported in other studies. However, an insignificant difference was found between the results of this study and those of studies by Lee et al. [1] $\left(47.8^{\circ} \pm 9.3^{\circ}\right.$ for PI, $11.5^{\circ} \pm 5.3^{\circ}$ for PT, and $36.3^{\circ} \pm 7.8^{\circ}$ for SS), Zhu et al. [17] $\left(44.6^{\circ} \pm 11.2^{\circ}\right.$ for PI, $11.2^{\circ} \pm 7.8^{\circ}$ for PT, and $32.5^{\circ} \pm 6.5^{\circ}$ for SS), and Le Huec and Hasegawa [19] $\left(52.0^{\circ} \pm 10.5^{\circ}\right.$ for PI, $11.6^{\circ} \pm 7.0^{\circ}$ for PT, and $40.2^{\circ} \pm 7.7^{\circ}$ for SS). We think that the differences between the values obtained using the EOS imaging system and those obtained using radiography were small. Therefore, a direct comparative study is needed (Table 7).

In this study, SS and PT showed statistically significant differences between sexes. The mean SS was $39.44^{\circ} \pm 8.13^{\circ}$ in males and $34.62^{\circ} \pm 5.84^{\circ}$ in females, and PT was $8.74^{\circ} \pm 5.50^{\circ}$ in males and $12.18^{\circ} \pm 6.27^{\circ}$ in females. However, Lee et al. [1] and Zhu et al. [17] have reported no significant difference in size according to sex (SS: $37.3^{\circ} \pm 7.1^{\circ}$ and $34.4^{\circ} \pm 8.6^{\circ}$ and PT: $11.4^{\circ} \pm 5.4^{\circ}$ and $11.6^{\circ} \pm 5.1^{\circ}$ in males and females, respectively, according to Lee et al. [1]).
Moreover, Janssen et al. [20] did not find any significant differences in SS and PT when comparing asymptomatic adult females with males. This study differs greatly from other studies in terms of the number of cases. Thus, the SS and PT values seemed to differ according to sex. Owing to the significant differences in the number of cases between men and women, we think that our results would be different from those of other studies. Therefore, the numbers of men and women should be equalized.

In the Pearson correlation analysis, correlations were found between PI and SS $(R=0.737, p<0.001)$, PI and PT $(R=0.659, p<0.001)$, and L1/S1 lordosis and SS $(R=0.616$, $p<0.001)$. Before discussing the correlation results, we must understand the concepts of PI, PT, and SS. Each measurement method is described in the measurement parameters. PI represents the shape of the pelvis and has a constant value (mean, $55^{\circ}$ ), and PT represents the position and degree of rotation of the pelvis. SS refers to the slope of the sacral bone, and SS is a factor reflecting the position of the sagittal lumbar spine, proportional to the PI. The sum of PT and SS is PI, and the formula "PI=PT+SS" has been established [21-24]. Moreover, in this study, since the R-value of PI and SS was lower than that of PI and PT, we assumed that PT acts as a determinant more than SS. Jiang et al. [25] have examined PT and PI in 55 patients with sagittal imbalance and found that the patients had significantly smaller PT and PI values than the normal group. Some studies have indicated that patients' symptoms also improved when the pelvic alignment in the sagittal plane improved after surgery for degenerative spinal disease [26-28]. As such, pelvic parameters are closely related to each other, and if one parameter is too large, it can be an exacerbating factor of lower lumbar spine and hip joint diseases. Thus, whenever performing spinal sur- 
gery, pelvic sagittal balance should always be considered.

This study has several limitations. First, the number of cases was small, which made it difficult for us to claim that our results represent the actual situation in young adults, and more data are needed to improve the reliability of our statistical results. Second, because the subjects were recruited from one region and university at one timepoint, the results might be biased to one side. Third, discussing the comparison of the results is difficult because the data were not directly compared with those from other studies and were compared only between each other. Fourth, EOS images were taken not only in the extended knee position but also in various knee angles. If the parameters for these various knee angles were measured and used in the analysis, we could have discovered other ways to maximize the use of the EOS imaging system.

\section{Conclusions}

In conclusion, we measured the spinopelvic sagittal values of young adults using the EOS imaging system. We hope that these values will be useful in treating spinopelvic diseases.

\section{Conflict of Interest}

Author Tae Kyun Kim has received research grants from the EOS manufacturing company. Except for that, no potential conflict of interest relevant to this article was reported.

\section{Acknowledgments}

The authors wish to thank all participants of the study.

\section{ORCID}

Youn Moo Heo: https://orcid.org/0000-0002-8739-2224; Tae Kyun Kim: https://orcid.org/0000-0003-1073-4211; Min Gu Jang: https://orcid.org/0000-0002-2001-0471; Jae Kyu Choi: https://orcid.org/0000-0002-3782-8827

\section{References}

1. Lee CS, Chung SS, Kang KC, Park SJ, Shin SK. Normal patterns of sagittal alignment of the spine in young adults radiological analysis in a Korean popu- lation. Spine (Phila Pa 1976) 2011;36:E1648-54.

2. Banno T, Togawa D, Arima H, et al. The cohort study for the determination of reference values for spinopelvic parameters (T1 pelvic angle and global tilt) in elderly volunteers. Eur Spine J 2016;25:3687-93.

3. Gutman G, Labelle H, Barchi S, Roussouly P, Berthonnaud E, Mac-Thiong JM. Normal sagittal parameters of global spinal balance in children and adolescents: a prospective study of 646 asymptomatic subjects. Eur Spine J 2016;25:3650-7.

4. Shimokawa T, Miyamoto K, Hioki A, et al. Compensatory pelvic retro-rotation associated with a decreased quality of life in patients with normal sagittal balance. Asian Spine J 2021 May 11 [Epub]. https:// doi.org/10.31616/asj.2020.0449.

5. Deschenes S, Charron G, Beaudoin G, et al. Diagnostic imaging of spinal deformities: reducing patients radiation dose with a new slot-scanning X-ray imager. Spine (Phila Pa 1976) 2010;35:989-94.

6. Escott BG, Ravi B, Weathermon AC, et al. EOS lowdose radiography: a reliable and accurate upright assessment of lower-limb lengths. J Bone Joint Surg Am 2013;95:e1831-7.

7. Delin C, Silvera S, Bassinet C, et al. Ionizing radiation doses during lower limb torsion and anteversion measurements by EOS stereoradiography and computed tomography. Eur J Radiol 2014;83:371-7.

8. Korovessis PG, Stamatakis MV, Baikousis AG. Reciprocal angulation of vertebral bodies in the sagittal plane in an asymptomatic Greek population. Spine (Phila Pa 1976) 1998;23:700-5.

9. Van Royen BJ, Toussaint HM, Kingma I, et al. Accuracy of the sagittal vertical axis in a standing lateral radiograph as a measurement of balance in spinal deformities. Eur Spine J 1998;7:408-12.

10. Vedantam R, Lenke LG, Keeney JA, Bridwell KH. Comparison of standing sagittal spinal alignment in asymptomatic adolescents and adults. Spine (Phila Pa 1976) 1998;23:211-5.

11. Vedantam R, Lenke LG, Bridwell KH, Linville DL, Blanke $\mathrm{K}$. The effect of variation in arm position on sagittal spinal alignment. Spine (Phila Pa 1976) 2000;25:2204-9.

12. Kim MS, Chung SW, Hwang C, Lee CK, Chang BS. A radiographic analysis of sagittal spinal alignment for the standardization of standing lateral position. J Korean Orthop Assoc 2005;40:861-7. 
13. Despres P, Beaudoin G, Gravel P, de Guise JA. Physical characteristics of a low-dose gas microstrip detector for orthopedic X-ray imaging. Med Phys 2005;32:1193-204.

14. Deschenes S, Godbout B, Pomero V, Skalli W, de Guise JA. Vertebral pose estimation using edge-based pattern matching and stereoradiographic $3 \mathrm{D}$ reconstruction of the spine. Int Congr Ser 2004;1268:23742.

15. Cresson T, Godbout B, Branchaud D, Chav R, Gravel P, De Guise JA. Surface reconstruction from planar $\mathrm{X}$-ray images using moving least squares. Annu Int Conf IEEE Eng Med Biol Soc 2008;2008:3967-70.

16. Legaye J, Duval-Beaupere G, Hecquet J, Marty C. Pelvic incidence: a fundamental pelvic parameter for three-dimensional regulation of spinal sagittal curves. Eur Spine J 1998;7:99-103.

17. Zhu Z, Xu L, Zhu F, et al. Sagittal alignment of spine and pelvis in asymptomatic adults: norms in Chinese populations. Spine (Phila Pa 1976) 2014;39:E1-6.

18. Sangondimath G, Mallepally AR, Marathe N, Salimath S, Chhabra HS. Radiographic analysis of the sagittal alignment of spine and pelvis in asymptomatic indian population. Asian Spine J 2021 May 10 [Epub]. https://doi.org/10.31616/asj.2020.0301.

19. Le Huec JC, Hasegawa K. Normative values for the spine shape parameters using 3D standing analysis from a database of 268 asymptomatic Caucasian and Japanese subjects. Eur Spine J 2016;25:3630-7.

20. Janssen MM, Drevelle X, Humbert L, Skalli W, Castelein RM. Differences in male and female spinopelvic alignment in asymptomatic young adults: a three-dimensional analysis using upright lowdose digital biplanar X-rays. Spine (Phila Pa 1976) 2009;34:E826-32.
21. Weinberg DS, Morris WZ, Gebhart JJ, Liu RW. Pelvic incidence: an anatomic investigation of 880 cadaveric specimens. Eur Spine J 2016;25:3589-95.

22. Schwab F, Lafage V, Patel A, Farcy JP. Sagittal plane considerations and the pelvis in the adult patient. Spine (Phila Pa 1976) 2009;34:1828-33.

23. Schwab F, Patel A, Ungar B, Farcy JP, Lafage V. Adult spinal deformity-postoperative standing imbalance: how much can you tolerate?: an overview of key parameters in assessing alignment and planning corrective surgery. Spine (Phila Pa 1976) 2010;35:2224-31.

24. Le Huec JC, Aunoble S, Philippe L, Nicolas P. Pelvic parameters: origin and significance. Eur Spine J 2011;20(Suppl 5):564-71.

25. Jiang WY, Xu RM, Ma WH, et al. Effect of reduction on spino-pelvic parameters in treating highgrade lumbar spondylolisthesis. Zhongguo Gu Shang 2014;27:726-9.

26. Than KD, Park P, Fu KM, et al. Clinical and radiographic parameters associated with best versus worst clinical outcomes in minimally invasive spinal deformity surgery. J Neurosurg Spine 2016;25:21-5.

27. Jiang L, Qiu Y, Xu L, et al. Sagittal spinopelvic alignment in adolescents associated with Scheuermann's kyphosis: a comparison with normal population. Eur Spine J 2014;23:1420-6.

28. Bourghli A, Aunoble S, Reebye O, Le Huec JC. Correlation of clinical outcome and spinopelvic sagittal alignment after surgical treatment of low-grade isthmic spondylolisthesis. Eur Spine J 2011;20(Suppl 5):663-8. 